\title{
Reseña de: Mario Docci, Emanuela Chiavoni. Saper leggere architettura. Bari [italia]: Editorial Laterza, Grandi Opere 2017
}

FABIANA AndREa CARBOnARI ${ }^{*}$ Laboratorio de Experimentación Gráfica Proyectual del Habitar. Facultad de Arquitectura y Urbanismo-Universidad Nacional de La Plata . (L'egraph-FAU-UNLP)

fabianacarbonari@yahoo.com.ar 
El pasado lunes 13 de marzo, en el Aula Magna de la Facultad de Arquitectura de la Universidad "Sapienza" de Roma, se presentó el libro "Sappere leggere l'architettura" escrito por los arquitectos Mario Docci y Emanuela Chiavoni y editado por la Editorial Laterza de Roma.

El texto constituye un actualizado e innovador abordaje del debate sobre la superación de "la ignorancia de la arquitectura y de la representación del espacio", temas planteados por Bruno Zevi en los primeros capítulos de "Saber ver la arquitectura". Publicado en 1948, el texto tuvo un gran significado en la formación básica de un importante número de estudiantes y jóvenes arquitectos que transitaron la Facultad de Arquitectura de Roma. De este modo y a casi 70 años de su primera edición, se plantea un retorno a las búsquedas gráficas como instrumentos para dar respuesta a los interrogantes que el espacio arquitectónico plantea.

La cuestión referida a la comprensión de la arquitectura a través del dibujo como medio de definición y visualización del proyecto o como herramienta para la comprensión de la obra, estuvo presente desde entonces en la escuela romana y fue desarrollada, entre otros, a lo largo de los años 60 a través de la obra del arquitecto Vincenzo Fasolo.

Siguiendo esta línea de acción los autores de "Saber leer la arquitectura", tal sería la traducción española del título, destacados profesores de la Facultad de Arquitectura de la Universidad de Roma, elaboraron un manual que refleja el rol insustituible del lenguaje gráfico para el conocimiento de la arquitectura. Mario Docci ha desarrollado una extensa y valiosa trayectoria académica. Fue fundador y director del Departamento de Relevamiento, Análisis y Dibujo del Ambiente y de la Arquitectura y de la Revista "Disegnare. Idee, Immagini". Ha conducido múltiples investigaciones que constituyen un gran aporte académico sobre temas relativos a las metodologías de relevamiento, registro y análisis gráfico, como así también a la historia de los métodos de representación. Emanuela Chiavoni, por su parte, es profesora de la Facultad de Arquitectura de la Universidad de Roma e integra el Comité Científico de la Revista "Disegnare. Idee, Immagini". Forma parte del Departamento de Historia, Dibujo y Restauración de la Arquitectura siendo responsable de su Archivo Histórico.

El libro se organiza a partir de dos instancias claramente diferenciadas. En una primera sección se definen las nociones teóricas del análisis gráfico. Se recurre al concepto de estructuralismo y su vinculación con el modelo gráfico en cuanto a proceso apto para realizar la reconstrucción de una obra de modo de evidenciar las reglas íntimas de su funcionamiento. Sobre la base de una metodología operativa desarrollada de modo pormenorizado, se apela a la semiología y a la lingüística, descomponiendo primero, para luego clasificar, componer y comparar cada parte con el todo espacial. A través de la síntesis y el despiece arquitectónico se estudian diferentes tópicos -análisis funcional, estructura portante, elementos constitutivos o análisis formal, espacial y relación entre la obra y el entorno-. Este procedimiento de lectura en el que el pensamiento gráfico cumple un rol fundamental, permite al "lector" analizar la arquitectura, transitar niveles progresivos de aproximación y adentrarse en ella hasta rescatar el más íntimo mensaje del autor.

En este proceso analítico de conocimiento de la compleja y difícilmente legible realidad arquitectónica, el dibujo constituye un instrumento sustancial. Parangonando el proceso con la investigación científica, se puede afirmar que se trata de generar modelos gráficos que permiten analizar y entender ideas proyectuales o espacios existentes. A la manera de la euritmia clásica, el dibujo se identifica con el modelo gráfico.... compuesto por un conjunto de elementos que están ligados entre sí mediante leyes con las cuales aparecen vinculados.

En la segunda sección del texto se analizan ejemplos significativos de la historia de la arquitectura con una modalidad ya satisfactoriamente empleada por Chiavoni en el texto "Il disegno di oratori romani. Rilievo e analisi di alcuni tra i piú significativi oratori di Roma", publicado en 2008 por Gangemi Editore. El discurso gráfico se complementa con el escrito para brindar una lectura acabada de las casi cincuenta obras estudiadas. Trazos simples y rigurosos definen plantas, cortes, vistas y perspectivas resueltas de acuerdo a precisos métodos geométricos matemáticos de representación espacial. El dibujo de registro permite recorrer la Acrópolis de Atenas, las más significativas obras del renacimiento hasta arribar al Ara Pacis y el MAXXI.

De este modo, la obra, inédita en lengua castellana, pone al servicio de todas aquellas personas vinculados con la disciplina arquitectónica, especialmente los estudiantes, una serie de signos y de códigos gráficos organizados de acuerdo a un método que posibilita el entendimiento profundo de la arquitectura, tanto contemporánea como aquella del pasado.

Se pone de manifiesto así una profunda integración de saberes a través de la participación mancomunada de diferentes disciplinas como la comunicación, los sistemas de representación, la historia de la arquitectura. De este modo, el libro permite diferentes lecturas, cada una de cuales será descubierta en función de los intereses del lector.

Finalmente cabe destacar que los dibujos y los textos, íntimamente vinculados, producen un placer visual de gran contenido y valor documental. En definitiva, retomando las palabras expresadas por el arquitecto Paolo Portoghesi en la presentación del texto "se trata de un entusiasmarte libro que es un himno al dibujo". 